\title{
Vitamin $C$ as well as $\beta$-carotene attenuates experimental liver fibrosis after intoxication with carbon tetrachloride in rats
}

\author{
Samuel WAMUTU ${ }^{1,2,3^{*}}$, Sven FRANCQUE ${ }^{2,6}$, Shyama CHATTERJEE ${ }^{3}$, \\ Emmanuel MUSISI ${ }^{1}$, George William MUYOMBYA ${ }^{4}$, Eric Van MARCK ${ }^{3,7}$, \\ Gabriel S. BIMENYA ${ }^{5}$ and Peter MICHIELSEN ${ }^{2,6}$
}

\author{
${ }^{I}$ Makerere University, College of Natural Sciences, Department of Biochemistry and Sports Science, \\ Kampala, Uganda. \\ ${ }^{2}$ Antwerp University Hospital, Department of Gastroenterology and Hepatology, Edegem, Belgium. \\ ${ }^{3}$ University of Antwerp, Faculty of Medicine and Health Sciences, Laboratory of Pathology, Antwerp, Belgium. \\ ${ }^{4}$ Makerere University, College of Veterinary Sciences, Department of Anatomy, Kampala, Uganda. \\ ${ }^{5}$ Makerere University, College of Health Sciences, Department of Pathology, Kampala, Uganda. \\ ${ }^{6}$ University of Antwerp, Faculty of Medicine and Health Sciences, \\ Laboratory of Experimental Medicine \& Paediatrics, Antwerp, Belgium. \\ ${ }^{7}$ Antwerp University Hospital, Laboratory of Pathology, Edegem, Belgium. \\ *Corresponding author, E-mail: swamutu@gmail.com, P. O. Box 7062; Kampala, Uganda; \\ Tel: +256-414-530555, Fax: +256-414-531061
}

\begin{abstract}
The therapeutic effects of vitamin $\mathrm{C}$ and $\beta$-carotene on chronic liver diseases have not yet been fully demonstrated and their application as dietary intakes or supplements lacks strong experimental backing. We aimed at investigating the therapeutic efficacy of these vitamins on hepatic fibrogenesis caused by carbon tetrachloride $\left(\mathrm{CCl}_{4}\right)$-intoxication in rats. Four groups of albino rats were used: group 1 (control) received only saline, whereas groups 2-4 were injected intraperitoneally with $0.5 \mathrm{~mL} / \mathrm{kg}$ body weight $\mathrm{CCl}_{4}$ every 3 days plus pentobarbital $(0.3 \mathrm{mg} / \mathrm{L})$ in drinking water for 10 weeks; after which $\mathrm{CCl}_{4}$ and pentobarbital were stopped and the animals in group 2 were allowed to rest, while those in groups 3 and 4 were treated with intramuscular injections $\left(100 \mathrm{mg} / \mathrm{kg} /\right.$ day) of vitamins $\mathrm{C}$ and $\beta$-carotene, respectively, for further 2 weeks. $\mathrm{CCl}_{4}$ plus pentobarbital resulted in well established fibrosis associated with notable steatosis and ballooning. Treatment with vitamin $\mathrm{C}$ or $\beta$-carotene modulated $\mathrm{CCl}_{4}$-induced liver pathology, as reflected by significantly lower histological scores $(\mathrm{p}<0.05)$. Vitamin $\mathrm{C}$ intervention was also associated with significantly lower levels of liver enzymes, unlike $\beta$-carotene. We conclude that compared to $\beta$-carotene, vitamin $C$ significantly ameliorated both biochemical and histological changes in $\mathrm{CCl}_{4}$-induced liver disease and that both vitamins separately attenuated liver fibrosis.
\end{abstract}

(C) 2012 International Formulae Group. All rights reserved.

Keywords: Albino rats, liver enzymes, hepatic fibrosis, histological scores, $\mathrm{CCl}_{4}$.

\section{INTRODUCTION}

Liver fibrosis is a common sequel of chronic liver diseases of whatever aetiology and is associated with high morbidity and mortality in affected patients (Wasmuth and Weiskirchen, 2010). Perceived as a wound-

(C) 2012 International Formulae Group. All rights reserved.

DOI : http://dx.doi.org/10.4314/ijbcs.v6i2.1 
healing response to a sustained liver injury $(\mathrm{Li}$ and Friedman, 1999), it may progress to cirrhosis and eventual liver failure (Wallace et al., 2008). The mechanisms underlying hepatic fibrosis are not entirely understood, but an increasing body of experimental and clinical data suggests a concurrent involvement of several key factors, including oxidative stress (Brenner, 2009) as a result of increased production of reactive oxygen species (ROS), thus overwhelming the cellular antioxidant defense mechanisms (Ha et al., 2010). Oxidative stress may prompt the quiescent hepatic stellate cells (also known as fat-storing or Ito cells) into proliferative, contractile myofibroblasts ( $\mathrm{Li}$ and Friedman, 1999; Friedman, 2008), which might also be sensitive to cytokines and chemokines secreted by liver-resident immuno-competent cells such as macrophages (Wallace et al. 2008; Wasmuth and Weiskirchen, 2010). Besides, continuous chemical or viral insults to the liver may also trigger several cascades of both cellular and extra-cellular reactions leading to increased production of collagen by the proliferating myofibroblasts ( $\mathrm{Li}$ and Friedman, 1999; Friedman, 2008).

To-date, there seems to be no effective and well-tolerated anti-fibrotic therapy, and the current treatment of hepatic fibrosis is only limited to either withdrawal or eradication of the injurious agent (Henderson and Forbes, 2008). A number of anti-fibrotic therapies such as colchicine for alcoholic cirrhosis (Cortez-Pinto et al., 2002), and interferon-gamma-1B for chronic hepatitic $\mathrm{C}$ (Pockros et al., 2007) have been tested in clinical trials but these have been met with poor success, as indeed, even the most recent efforts are just only promising (Ghiassi-Nejad and Friedman, 2008; Cohen-Naftaly and Friedman, 2011). However, several epidemiological studies have quite strongly associated high intake of fruits and vegetables with low incidences of chronic and/or degenerative diseases (Corrao et al., 2004; Martinez-Gonzalez et al., 2011).
Dietary components such as carotenoids (Krinsky, 1998; Paiva and Russell, 1999) and vitamin C (Padayatty et al 2003) have been pursued for their therapeutic potential in chronic diseases. Owing to their antioxidant properties (Ha et al., 2010) they are cautiously considered to protect tissues against ROS-mediated injury (Seifert et al., 1995; Oyimbo et al., 2006). Nevertheless, both experimental and clinical studies on the role of dietary antioxidants in liver diseases have so far led to mixed findings (Bjelakovic et al., 2011). The aim of the present study was to evaluate the therapeutic effects of vitamin $\mathrm{C}$ and $\beta$-carotene, respectively, against carbon tetrachloride $\left(\mathrm{CCl}_{4}\right)$ induced liver fibrosis in rats.

\section{MATERIALS AND METHODS}

For this study, male Wistar albino rats (total number $=38$ ), weighing between 190$210 \mathrm{~g}$ each were purchased from the Small Animal Breeding House (Makerere University College of Veterinary Medicine and Animal resources, Kampala). The methods involving the use of animals were approved by the National Council of Science and Technology in Uganda (UNCST), through Makerere University Research \& Publication Ethical Committee on the Care and Use of Laboratory Animals. The animals were handled humanely and allowed free access to food and drinking water throughout the study period, and the investigators fully complied with the statutory and institutional regulations.

\section{Chemicals and reagents}

The chemicals and reagents were of analytical grade (AnalaR) and they included vitamin $\mathrm{C}$ (ascorbic acid), solvents toluol and isopropanol which were obtained from BDH Laboratory Supplies, Poole, England. Beta carotene (a water-soluble derivative) was purchased from Pharminnova N.V., Waregem (Belgium), and sodium pentobarbital from Certa N.V., Braine-l'Alleud (Belgium). Olive oil was a product of Loreto Speciality Foods, 
Espartinas (Spain). Paraffin wax (paraplast plus) came from McCormick Scientific, St. Louis (USA), and stains haematoxylin, eosin and Masson's trichrome were from Merck Chemicals Co. (USA).

\section{Experimental design}

The rats were randomly divided into four groups of 8 or 10 animals each and allowed one (1) week of acclimatisation to the laboratory environment. The 4 groups were treated as follows: Group 1 (the controls) received intraperitoneal (IP) injections of $0.9 \%$ saline every 3 days for 10 weeks. Groups 2, 3 and 4 were injected intraperitoneally (IP) with $0.5 \mathrm{~mL} / \mathrm{kg}$ body weight $\mathrm{CCl}_{4}$ (diluted 1:1 with olive oil) every 3 days plus pentobarbital $(0.3 \mathrm{mg} / \mathrm{L})$ in drinking water for 10 weeks. At the end of this period, $\mathrm{CCl}_{4}$ and pentobarbital treatments were stopped. The animals in group 2 received neither of the vitamin treatments while those in groups 3 and 4 were treated with intramuscular (IM) injections (100 $\mathrm{mg} / \mathrm{kg} /$ day) of vitamins $\mathrm{C}$ and $\beta$-carotene, respectively, for further 2 weeks. In this protocol, the minute amounts of pentobarbital in drinking water were to boost $\mathrm{CCl}_{4}$ toxicity in rats as previously reported (McLean et al., 1969; Wamutu, et al., 2011). The $\mathrm{CCl}_{4}$ and vitamin dosages used were adapted from the existing literature (Canturk et al., 1999; Abe et al., 2007). At week 12, the rats in all groups were deeply anaesthetised and bled by cardiac puncture. The blood was collected for biochemical analyses and the livers were removed for histological examination.

\section{Biochemical measurements}

The serum enzyme activities of alanine aminotransferase (ALT), aspartate aminotransferase (AST), alkaline phosphatase (ALP) and gamma glutamyltranspeptidase (GGT) as well as the total bilirubin (Tbil) serum levels were measured using a Clinical Chemistry automated analyser, Cobas Integra 400 Plus (Roche Diagnostics, GMBH,
Germany), a facility located at Clinical Chemistry Laboratory of Mulago Hospital Complex, the National Referral Hospital in Kampala, Uganda.

\section{Histological examination}

For histological examinations, whole livers were quickly removed, rinsed in cold phosphate buffered saline (PBS), mopped dry and weighed. Small portions of the liver tissues were randomly cut from at least 2 different lobes and fixed in $10 \%$ buffered formalin. The tissues were processed according to Bancroft and Gamble (2002) and paraffin-embedded tissue blocks were sectioned (5 $\mu \mathrm{M}$ thickness) using a bench microtome (MICROM International, $\mathrm{GmbH}$, model STP120, Germany). The sections were subsequently deparaffinised and stained with haematoxylin and eosin (H\&E). To evaluate the degree of hepatic fibrosis, Masson's trichrome stain was used as delicate septa characteristic of early bridging fibrosis may not be easily observable on H\&E (Harris EI et al., 2009). The slides were viewed under light microscopy to compare the experimental and control liver morphology. The histopathological changes were scored by a qualified pathologist blinded of the study groups using a modification from Bedossa and Poynard (1996) and Brunt et al. (1999) systems of grading and staging. The major histological changes observed were subjected to a scoring system described in Table 1 .

\section{Statistical Analysis}

The data were analysed using SPSS version 15 software for Windows (SPSS Inc., Chicago IL, USA). Biochemical data were expressed as mean \pm SEM. The differences among different groups were determined using unpaired Student's t-test followed by a post-hoc test. Histology scores were analysed using Kruskal-Wallis non-parametric test. Pvalues of less than 0.05 were considered to be significant. 


\section{RESULTS}

Carbon tetrachloride $\left(\mathrm{CCl}_{4}\right) \quad$ IP injections in albino rats plus small amounts of pentobarbital in drinking water for 10 weeks led to substantial non-uniform nodularity on the liver surfaces. The livers in group $2\left(\mathrm{CCl}_{4}\right.$ alone) exhibited a strong yellow tint, apparently manifesting severe anomaly. Examination under light microscopy of the sections from group 2 revealed thick fibrotic septa associated with some degree of hepatocytic ballooning and steatosis (Figure 1). On intervention, IM treatment with either vitamin $\mathrm{C}$ or $\beta$-carotene for 2 weeks after $\mathrm{CCl}_{4}$ resulted in significantly less severe liver histology in groups 3 (Figure 2) and 4 (Figure 3 ), respectively, as expressed by significantly lower scores for ballooning (Figure 4), steatosis (Figure 5) and fibrosis (Figure 6) in the vitamin-treated groups. The changes in all experimental groups (whether treated with vitamin or not) were strongly associated with severe portal, periportal mixed lymphocytic infiltrates and neutrophilic granulocytes. This inflammation, however, was not significantly ( $p>0.05$ ) different between the vitamin-treated groups and $\mathrm{CCl}_{4}$ untreated group (Table 2).

The damage of the liver was further investigated by assaying for indicator enzymes in the serum. Typically, serum ALT, AST, ALP, and GGT were measured in both the control and the test groups. Biochemical results indicated significantly higher $(\mathrm{p}<0.05)$ levels of serum ALT and AST in $\mathrm{CCl}_{4}$ group 2 compared to the control (Figure 7). Vitamin $\mathrm{C}$ and $\beta$-carotene intervention in groups 3 and 4 , respectively, led to significantly lower levels of these serum transaminases as compared to $\mathrm{CCl}_{4}$ group 2 which remained untreated (all $\mathrm{p}<0.05)$. GGT and ALP seemed to follow the same pattern (Figure 7), with their respective levels highly raised in $\mathrm{CCl}_{4}$ group $2(\mathrm{p}<0.05)$. Moreover, vitamin treatment in groups 3 and 4 was associated with significantly low activity levels of these enzymes when compared to the untreated group 2 (both $\mathrm{p}<0.05)$.

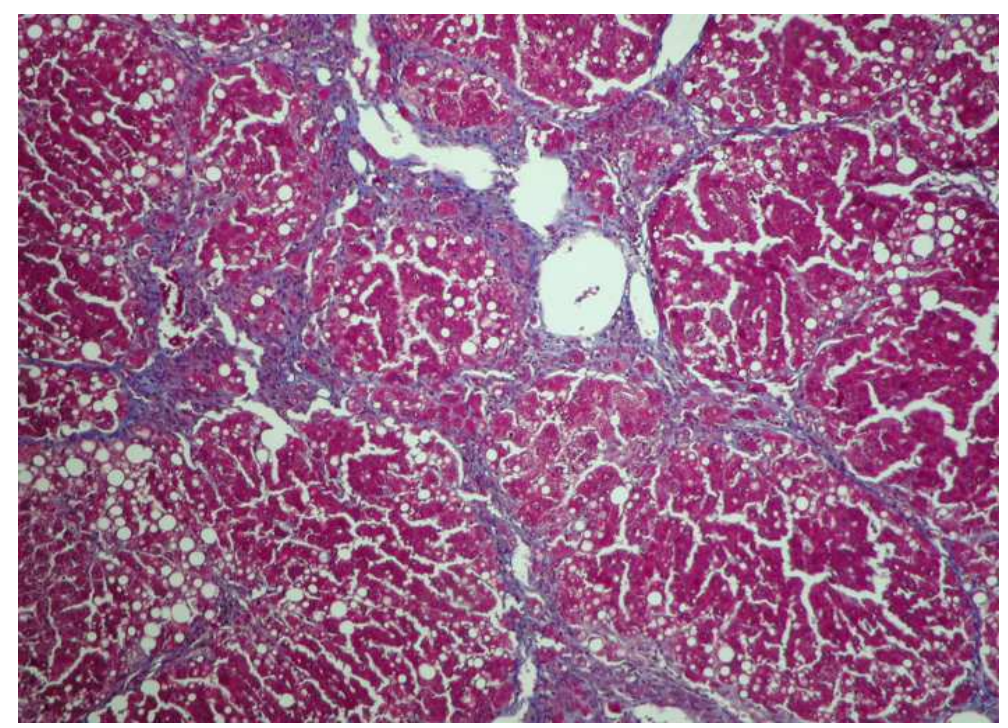

Figure 1: Liver section from group 2 given $\mathrm{CCl}_{4}$ for 10 weeks; No intervention. Note the significant fibrosis and moderate steatosis (Masson's trichrome, $\mathrm{x} 20$ ). 


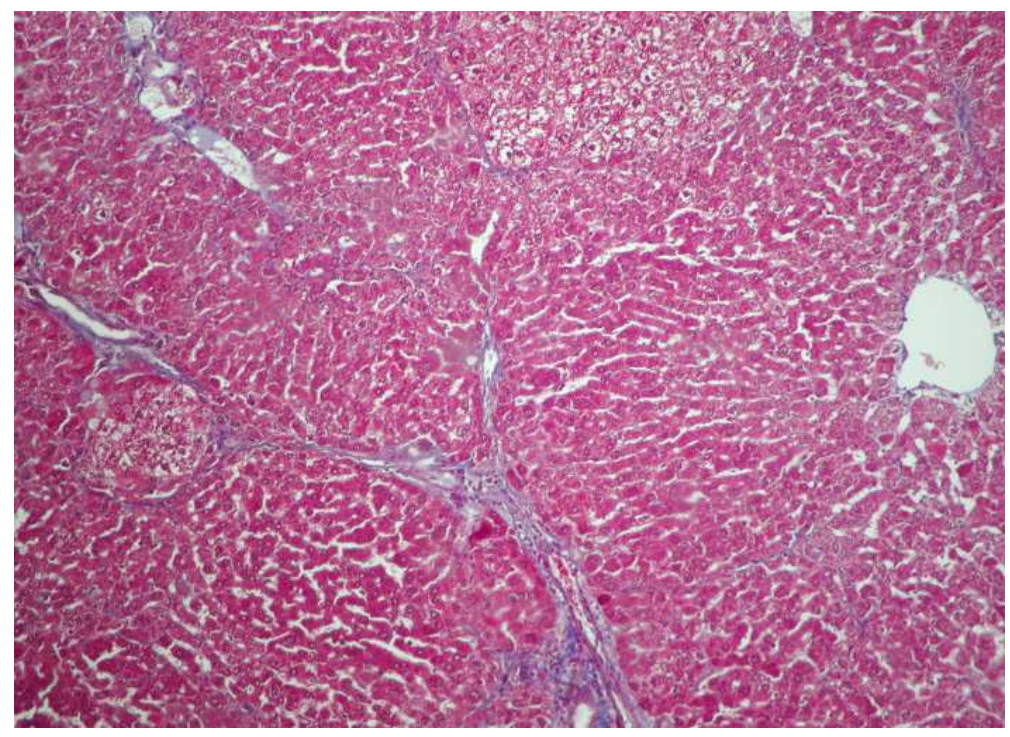

Figure 2: Liver histology section from group 3 given $\mathrm{CCl}_{4}$ for 10 weeks, then treated with vitamin $\mathrm{C}$ for 2 weeks. Less fibrosis and almost no steatosis are observed (Masson's trichrome, x20).

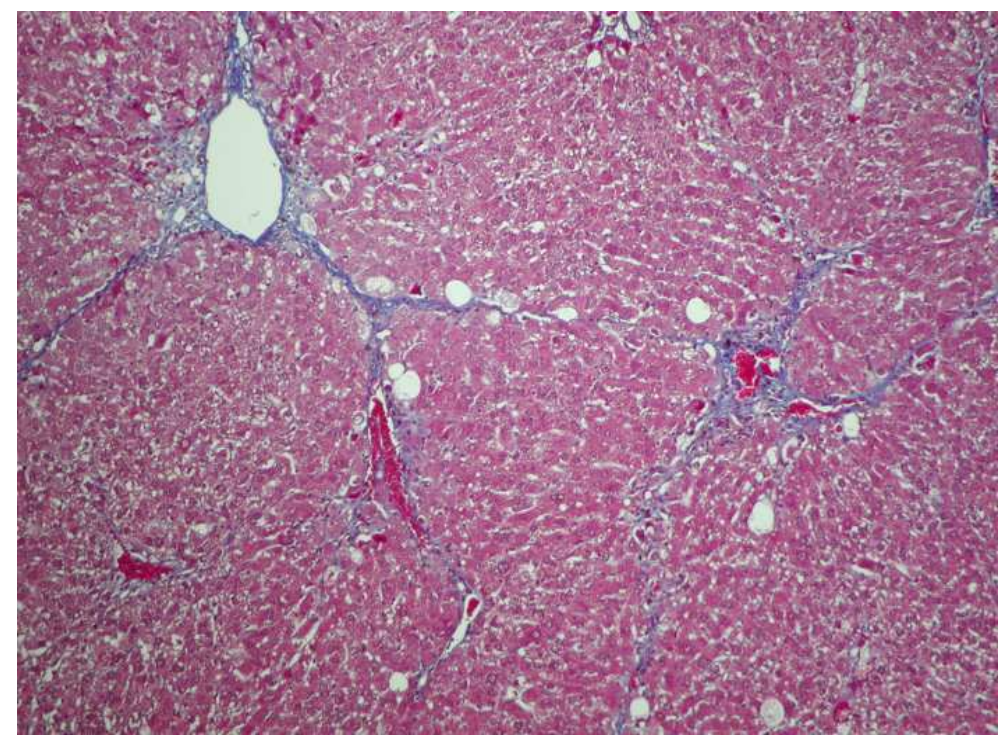

Figure 3: Liver histology section from group 4 given $\mathrm{CCl}_{4}$ for 10 weeks, then treated with $\beta$-carotene for 2 weeks. Note the moderate fibrosis and mild steatosis (Masson's trichrome, $\mathrm{x} 20)$. 


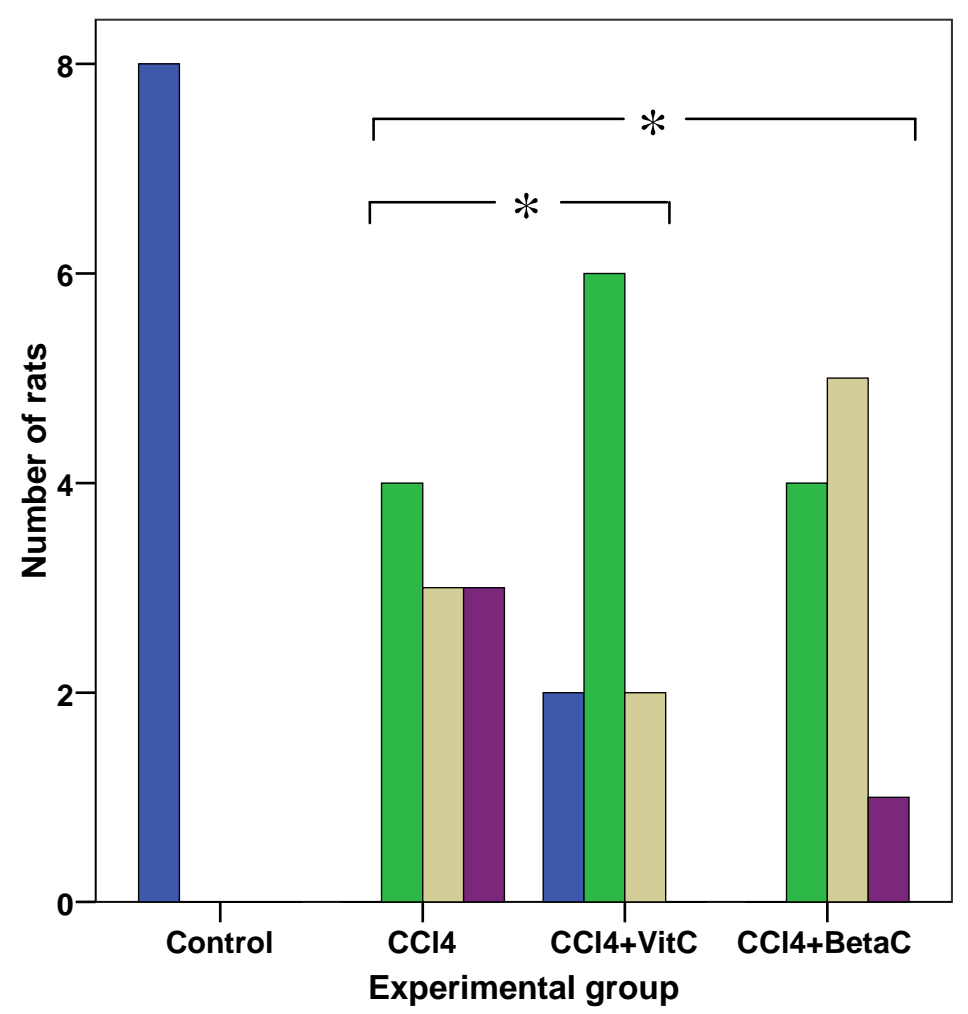

Ballooning (0-3)

$\square$ Score 0

$\square$ Score 1

$\square$ Score 2

Score 3

Compared to $\mathrm{CCl}_{4}$ group, ${ }^{*}<0.05$ (+VitC and $+\mathrm{BetaC}$ groups). Abbreviations: $\mathrm{CCl}_{4}$, carbon tetrachloride; VitC, vitamin C; BetaC, $\beta$-carotene.

Figure 4: Histogram showing the number of animals for each grade of ballooning in the control and experimental groups.

\section{DISCUSSION}

Dietary vitamins have been suggested to be modulators of liver disease but the information available to date shows mixed results. We examined the possible effects of vitamin $\mathrm{C}$ and $\beta$-carotene on liver injury caused by chronic $\mathrm{CCl}_{4}$ intoxication in rats. $\mathrm{CCl}_{4}$ administration IP plus minute amounts of pentobarbital in drinking water for 10 weeks resulted in well established fibrosis associated with notable steatosis and ballooning of the hepatocytes. $\mathrm{CCl}_{4}$ also significantly increased activity levels of serum ALT, AST, GGT and ALP. These changes are consistent with several previous studies that used $\mathrm{CCl}_{4}$-animal model for induction of experimental liver disease (Seifert et al., 1995; Canturk et al., 1999; Abe et al., 2007).
Vitamin C intervention significantly attenuated most of the histological and biochemical changes when compared to the $\mathrm{CCl}_{4}$ group which was not treated with the vitamin. This water-soluble vitamin is considered to be a powerful quencher of free radicals/reactive species, in part, because of its ease to oxidation and the resulting semidehydroascorbic acid radical assumes relative stability (Halliwell, 2001; Griffiths \& Lunec, 2001). ROS (oxygen derived free radicals) are increasingly being incriminated as playing pivotal role in many chronic diseases such as hepatic fibrogenesis (Brenner, 2009). More recently vitamin C has been reported to be effective in modulating different kinds of liver damage as demonstrated by various animal models (Abhilash et al., 2011; Wamutu et al., 2011), 
most probably through its ability to neutralise ROS, although such benefit would perhaps be less than anticipated or even elusive in human studies (Padayatty et al., 2003). Nonetheless, vitamin $\mathrm{C}$, in combination with other vitamins such as vitamin E, has shown favourable antifibrotic effects in patients with non-alcoholic steatohepatitis (Harrison et al., 2003) and fatty liver disease (Ersoz et al., 2005). Moreover, several disease conditions that are perceived to be caused or exacerbated by free radicals are also associated with low plasma and tissue vitamin C levels. Furthermore, vitamin C concentration could diminish in patients with liver diseases and possibly other chronic disorders (Padayatty et al. 2003). It may not be clear, though, whether sub-optimal vitamin $\mathrm{C}$ in such patients contributes to liver diseases, is a consequence of the pathophysilogical process or just a coincident entity. Nevertheless, vitamin $\mathrm{C}$ may still be a promising therapeutic drug for some liver diseases.

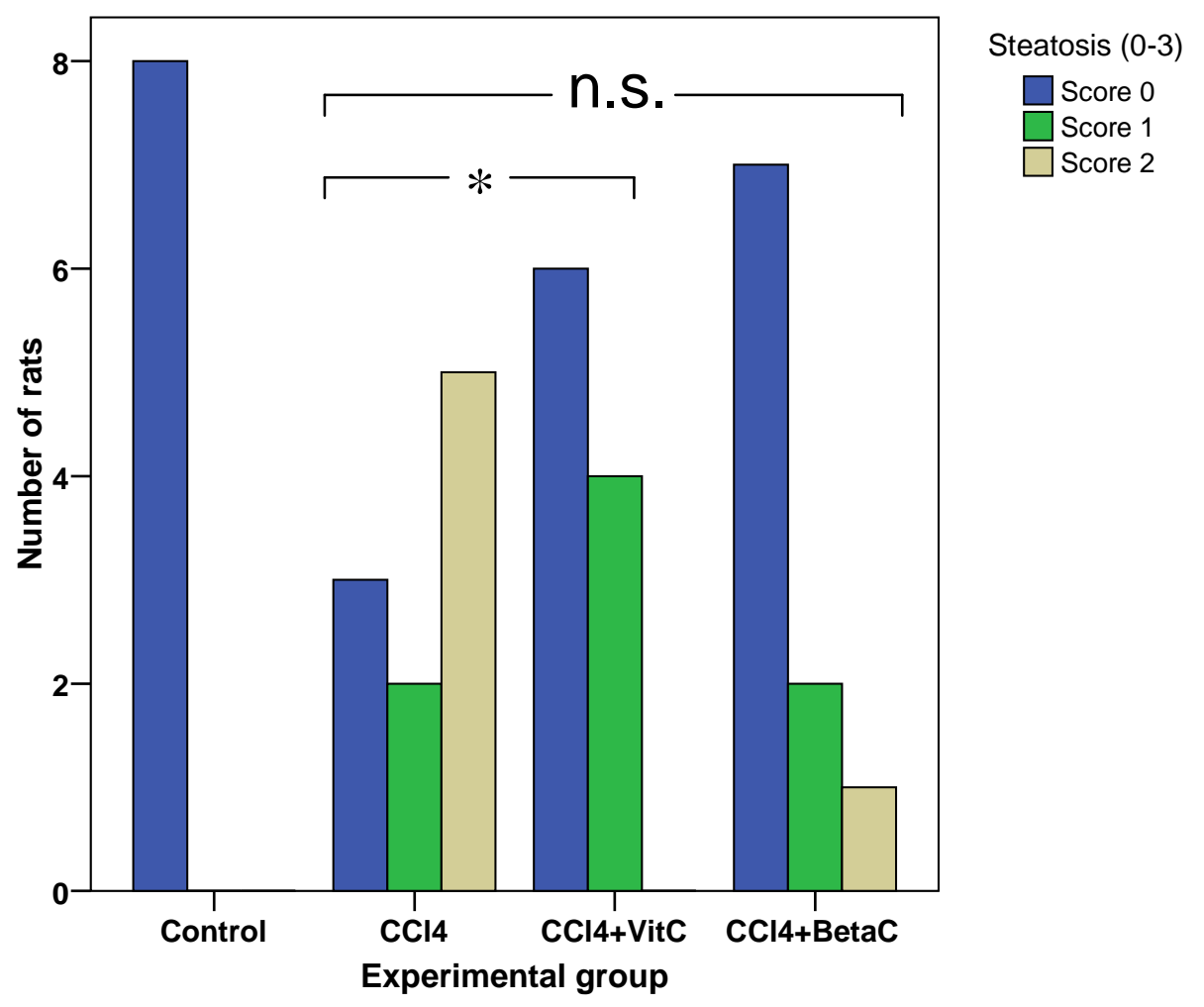

Compared to $\mathrm{CCl}_{4}$ group, ${ }^{*} \mathrm{p}<0.05$ (+VitC group); ${ }^{\text {n.s. }}$ Not significant (+BetaC group). Abbreviations: $\mathrm{CCl}_{4}$, carbon tetrachloride; VitC, vitamin $\mathrm{C}$; BetaC, $\beta$-carotene.

Figure 5: Histogram showing the number of animals for each grade of steatosis in the control and experimental groups. 


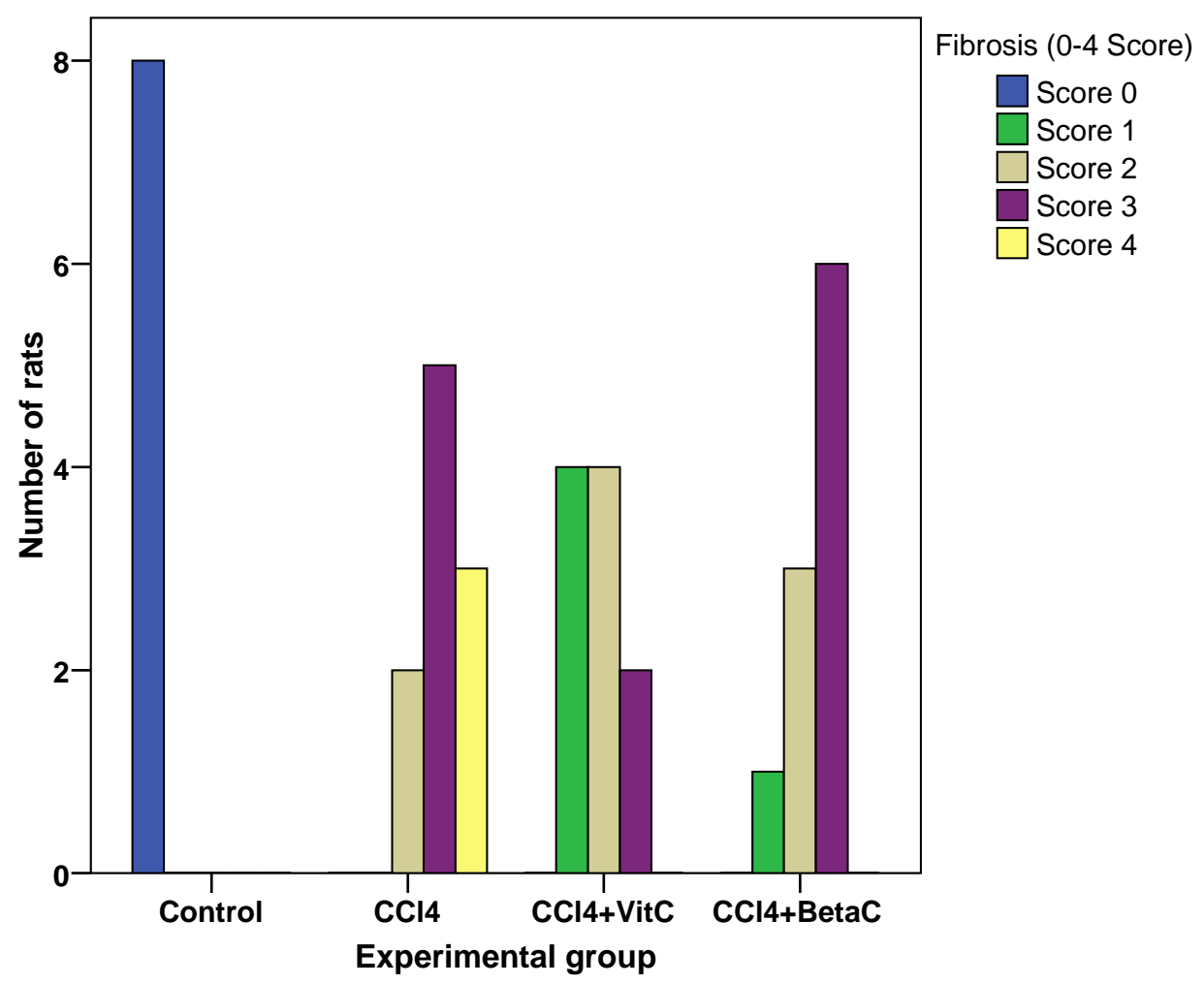

Compared to $\mathrm{CCl}_{4}$ group, ${ }^{*} \mathrm{p}<0.01$ (+VitC \& + BetaC groups).

Abbreviations: $\mathrm{CCl}_{4}$, carbon tetrachloride; VitC, vitamin $\mathrm{C}$; BetaC, $\beta$-carotene.

Figure 6: Histogram showing the number of animals for each grade of fibrosis in the control and experimental groups.

Similarly, $\beta$-carotene, applied in moderate doses led to lower scores for most of the histopathologic alterations, except for hepatic inflammation $(p>0.05)$ as compared to the $\mathrm{CCl}_{4}$ group 2. This was surprising because in previous studies, $\beta$-carotene had shown limited benefit when co-administered with $\mathrm{CCl}_{4}$ in a prophylactic setting. It was shown to exacerbate steatosis and to very poorly influence the biochemical outcomes (Wamutu et al., 2011). This difference may be explained, perhaps partly, by the fact that in the former study, $\mathrm{CCl}_{4}$ was applied simultaneously with $\beta$-carotene, and in the present study, the vitamin was given after $\mathrm{CCl}_{4}$ and pentobarbital administration was stopped. Therefore, one would expect a conceivable self-healing of the liver rather than the effect of $\beta$-carotene, or the vitamin could have simply enhanced the reversal of fibrosis, without causing side effects usually associated with adverse interactions of this vitamin and other substances (Leo \& Lieber, 1999). Nonetheless, the present results corroborate previous findings by Seifert et al. (1995) and Wardi et al. (2001) in which $\beta$ carotene was reported to have modulated the severity of hepatic inflammation and fibrosis. Nevertheless data from some clinical reports indicate that prolonged and continuous doses of vitamin A (an immediate metabolite of $\beta$ carotene) even in would-be low "therapeutic" range can result in chronic liver disease (Geubel et al., 1991; Jorens et al., 1992) suggesting that its usefulness could still be limited. 

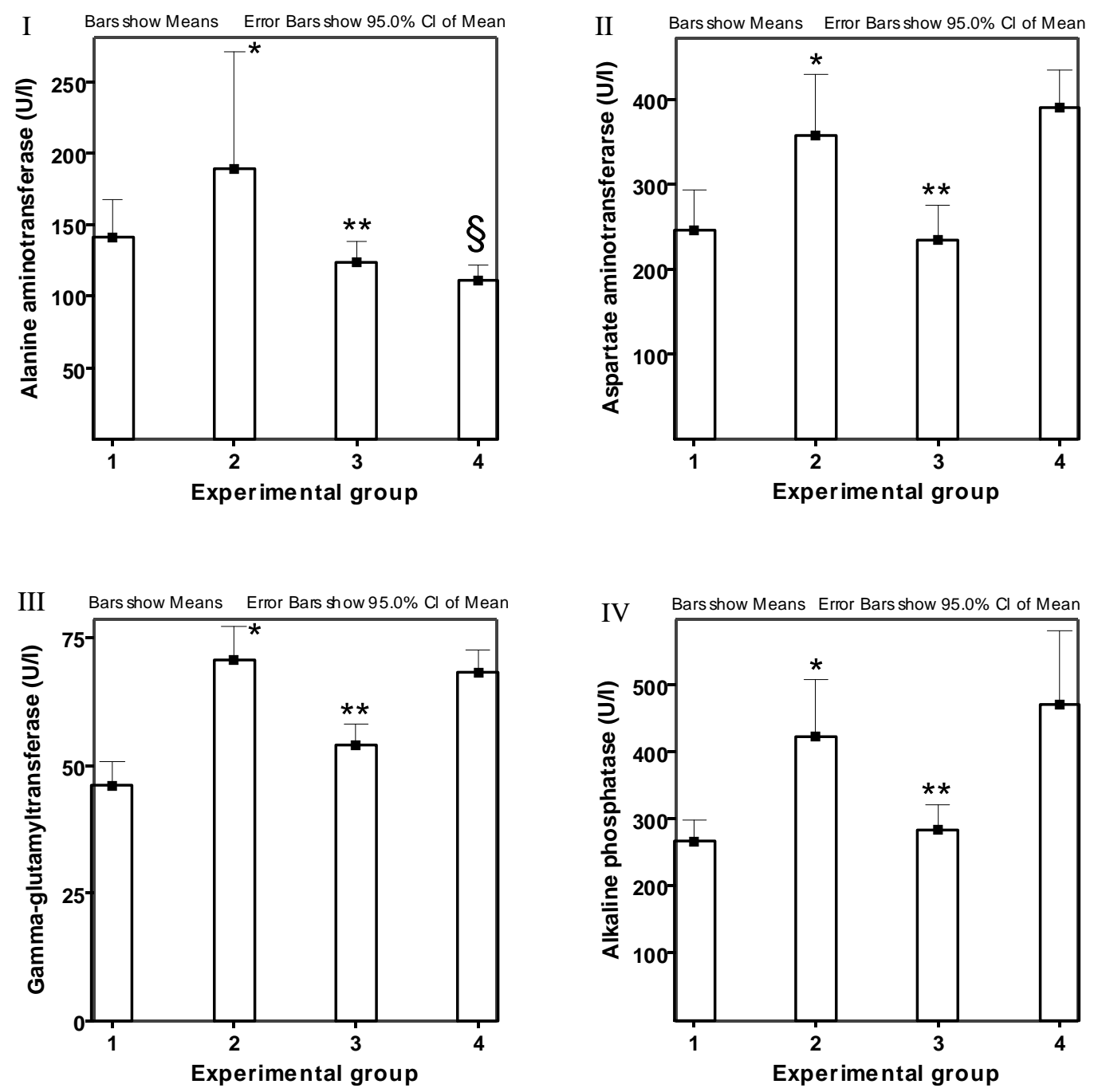

Compared to control, ${ }^{*} \mathrm{p}<0.05\left(\mathrm{CCl}_{4}\right.$ group); Compared to $\mathrm{CCl}_{4}$ group $2,{ }^{* *} \mathrm{p}<0.05$ (+VitC group 3 ); ${ }^{8} \mathrm{p}<0.05$ (+BetaC group 4); Abbreviations: ALT, alanine aminotransferase; AST, aspartate aminotransferase; GGT, gamma-glutamyltranspeptidase; ALP, alkaline phosphatise.

Figure 7: Serum enzyme activity levels of ALT (I), AST (II), GGT (III) and ALP (IV) in control and experimental groups. 
S. WAMUTU et al. / Int. J. Biol. Chem. Sci. 6(2): 559-571, 2012

Table 1: Numerical scores for grading and staging of major histopathhological changes in rat liver sections.

\begin{tabular}{|c|c|c|c|c|}
\hline Portal inflammation & Lobular inflammation ${ }^{\delta}$ & Ballooning $^{\dagger}$ & Steatosis $^{\text {II }}$ & Fibrosis \\
\hline $0=$ none & $0=$ none & $0=$ none & $0=$ no steatosis & $0=$ no fibrosis \\
\hline $\begin{array}{l}1=\text { mild }(\text { few portal tracts }) \\
2=\text { moderate }(\text { some portal tracts) } \\
3=\text { marked (most portal tracts) }\end{array}$ & $\begin{array}{l}1=1-2 \text { foci } \\
2=2-4 \text { foci } \\
3=>4 \text { foci }\end{array}$ & $\begin{array}{l}1=\text { few cells } \\
2=\text { many } \\
3=\text { very many }\end{array}$ & $\begin{array}{l}1=\leq 33 \% \\
2=33-66 \% \\
3=>66 \%\end{array}$ & $\begin{array}{l}1=\text { mild PP } \\
2=\text { portal-PP } \\
3=\text { bridging P-P \& P-C linkages } \\
4=\text { fibrous septa, disturbed architecture, } \\
\text { nodulation }\end{array}$ \\
\hline
\end{tabular}

Abbreviations: P, Portal; PP, Peri-portal; P-P, Portal-portal; P-C, Portal-central.

"Modified from: Brunt et al., 1999.

Table 2: p-Values of Kruskal-Wallis non-parametric test for histology scores between $\mathrm{CCl}_{4}$ group 2 and vitamin-treated groups 3 and 4 .

\begin{tabular}{|c|c|c|c|c|c|c|c|}
\hline & \multicolumn{2}{|c|}{ Inflammation } & \multirow{2}{*}{ Necrosis } & \multirow{2}{*}{ Apoptosis } & \multirow{2}{*}{ Ballooning } & \multirow{2}{*}{ Steatosis } & \multirow{2}{*}{ Fibrosis } \\
\hline & Portal & Lobular & & & & & \\
\hline Possible scores & $0-3$ & $0-3$ & $0-2$ & $0-2$ & $0-3$ & $0-3$ & $0-4$ \\
\hline VitC-treated/CCl 4 & 0.275 & 0.075 & $0.029 *$ & 0.131 & $0.027 *$ & $0.043 *$ & $0.004 *$ \\
\hline BetaC-treated/CCl${ }_{4}$ & 0.316 & 0.165 & $0.049 *$ & 0.163 & $0.044 *$ & 0.059 & $0.006^{*}$ \\
\hline
\end{tabular}

* $\mathrm{p}<0.05$ compared to $\mathrm{CCl}_{4}$ group; $\mathrm{CCl}_{4}$, carbon tetrachloride; VitC, vitamin C; BetaC, $\beta$-carotene 
That $\beta$-carotene did not cause any complications, as reflected by our present results, can also be explained, at least in part, on the basis of its conversion to vitamin A (retinol) which is perceived as a potentially toxic, especially in the presence of other drugs such as alcohol. However, if the hepatic reserves of vitamin A are not disturbed, this conversion is usually well controlled and occurs only according to body's needs, and this may have rendered the pro-vitamin A less toxic in our experiments.

\section{Conclusion}

Our results demonstrate that vitamin $\mathrm{C}$ significantly attenuates liver damage caused by $\mathrm{CCl}_{4}$ intoxication and induces reversal of hepatic fibrosis, including other changes in rats. The present results also show that $\beta$ carotene modulates liver fibrosis without significantly affecting liver enzyme activities. Both vitamins appear promising as antifibrotic agents in experimental models and encourage further studies.

\section{ACKNOWLEDGEMENTS}

This work was supported by a grant from Innovation at Makerere University (I@MAK) Funds, a mixed scholarship from the Belgian Government through the Belgian Technical Co-operation (BTC) and a Short Research Stay (SRS) in Belgium by the Flemish Inter-university Council-University Development Cooperation (VLIR-UOS). S. W. was a recipient of the grant and the scholarships.

\section{REFERENCES}

Abe W, Ikejima K, Lang T, Okumura K, Enomoto N, Kitamura T, Takei Y, Sato N. 2007. Low molecular weight heparin prevents hepatic fibrogenesis caused by carbon tetrachloride in the rat. $J$. Hepatol., 46: 286-294.
Abhilash PA, Harikrishnan R, Indira M. 2011. Ascorbic acid supplementation downregulates the alcohol induced oxidative stress, hepatic stellate cell activation, cytotoxicity and mRNA levels of selected fibrotic genes in guinea pigs. Free Radic. Res. 2011 Dec 8 [Epub ahead of print].

Bancroft J, Gamble M. 2002. Theory and Practice of Histological Techniques $\left(5^{\text {th }}\right.$ Edn). Publisher Churchill Livingstone: London, U.K.

Bedossa P, Poynard T. 1996. An algorithm for the grading of activity in chronic hepatitis C. The METAVIR Cooperative Study Group. Hepatology, 24: 289-293.

Bjelakovic G, Gluud LL, Nikolova D, Bjelakovic M, Nagorni A, Gluud C. 2011. Antioxidant supplements for liver diseases. Cochrane Database Syst. Rev., 16(3): CD007749.

Brenner DA. 2009. Molecular pathogenesis of liver fibrosis. Trans Am. Clin. Climatol. Assoc., 120: 361-368.

Brunt EM, Janney CG, Di Besceglie AM, Neuschwander-Tetri BA, Bacon BR. 1999. Nonalcoholic steatohepatitis: a proposal for grading and staging the histological lesions. Am. J. Gastroenterol., 94: 2467-2474.

Canturk Z, Canturk NZ, Ozbilim G, Yenisey C. 1999. Experimental cirrhosis of the liver and cytoprotective effects of alpha tocopherol. E. A. Med. J., 76: 223-227.

Cohen-Naftaly M and Friedman SL. 2011. Current status of novel antifibrotic therapies in patients with chronic liver disease. Therap. Adv. Gastroenterol., 4(6): 391-417.

Corrao G, Zambon A, Bagnardi V, Arico S, Loguercio C, D'Amicis A, Collaborative SIDECIR Group. 2004. Nutrient intakes, nutritional patterns and the risk of liver cirrhosis: an explorative case-control study. Eur. J. Epidemiol., 19(9): 861-869. 
Cortez-Pinto H, Alexandrino P, Camilo ME, Gouveira-Oliveira A, Santos PM, Alves MM, Moura MC. 2002. Lack of effect of colchicine in alcoholic cirrhosis: final results of a double blind randomized trial. Eur. J. Gastroenterol. Hepatol., 14(4): 377-381.

Ersoz G, Gunsar F, Karasu Z, Akay S, Batur Y, Akarsa US. 2005. Management of fatty liver disease with vitamin $\mathrm{E}$ and $\mathrm{C}$ compared to ursodeoxycholic acid treatment. Turk. J. Gastroenterol., 16: 124-138.

Friedman SL. 2008. Mechanisms of hepatic fibrogenesis. Gastroenterology, 134(6): 1655-1669.

Ghiassi-Nejad Z, Friedman SL. 2008. Advances in anti-fibrotic therapy. Expert Rev. Gastroenterol. Hepatol., 2(6): 800816.

Geubel AP, De Galocsy C, Alves N, Rahier J, Dive C. 1991. Liver damage caused by therapeutic vitamin A administration: estimate of dose-related toxicity in 41 cases. Gastroenterol., 100(6): 17011709.

Griffiths HR, Lunec J. 2001. Ascorbic acid in the $21^{\text {st }}$ century - more than a simple antioxidant. Environ. Toxicol. Pharmacol., 10(4): 173-182.

Ha HL, Shin HJ, Feitelson MA, Yu DY. 2010. Oxidative stress and antioxidants in hepatic pathogenesis. World J. Gastroenterol., 16(48): 6035-6043.

Halliwell B. 2001. Vitamin C and genomic stability (A Review). Mutat. Res., 475(12): 29-35

Harris IE, Washington K, Lamps WL. 2009. Acute and chronic infectious hepatitis. In Surgical Pathology of the GI Tract, Liver, Billiary Tract and Pancreas, Odze RD, Goldblim JR (Eds). Saunders, Elsivier.

Harrison SA, Torgerson S, Hayashi P, Ward J, Schenker S. 2003. Vitamin E and vitamin $\mathrm{C}$ treatment improves fibrosis in patients with non-alcoholic steatohepatitis. Am. J. Gastroenterol., 98: 2485-2490.

Henderson NC, Forbes SJ. 2008. Hepatic fibrogenesis: from within and outwith. Toxicology., 254(3): 130-135.

Jorens PG, Michielsen PP, Pelckmans PA, Fevery J, Desmet VJ, Geubel AP, Rahier J, Van Maercke YM. 1992. Vitamin A abuse: development of cirrhosis despite cessation of vitamin A. A six year clinical and histopathologic follow-up. Liver, 12: 381-386.

Krinsky, NI. 1998. The antioxidant and biological properties of the carotenoids; Ann. N.Y. Acad. Sci., 854: 443-447.

Leo MA, Lieber CS. 1999. Alcohol, vitamin $A$, and $\beta$-carotene: adverse interactions, including hepatotoxicity and carcinogennicity - A Review. Am. J. Clin. Nutr., 69: 1071-1085.

Li D, Friedman SL. 1999. Liver fibrogenesis and the role of hepatic stellate cells: new insights and prospects for therapy. $J$. Gastroenterol. Hepatol., 14(7): 618-633.

Martinez-Gonzalez MA, de la FuenteArrillaga C, Lopez-Del-Buro C, VazquezRuiz Z, Benito S, Ruiz-Canela M. 2011. Low consumption of fruit and vegetables and risk of chronic disease: a review of the epidemiological evidence and temporal trends among Spanish graduates. Public Health Nutr., 14(12): 2309-2315.

McLean E, McLean AEM, Sutton PM. 1969. Instant cirrhosis. An improved method for producing cirrhosis of the liver in rats by simultaneous administration of carbon tetrachloride and phenobarbitone; $\mathrm{Br} . \mathrm{J}$. Exp. Pathol., 50: 502-506.

Oyinbo CA, Dare WN, Okogun GRA, Anyanwu LC, Ibeabuchi NM, Noronha CC, Okanlawon OA. 2006. The hepatoprotective effect of vitamin $\mathrm{C}$ and $\mathrm{E}$ on hepatotoxicity induced by ethanol in 
Sprague Dawley rats. Pak. J. Nutr., 5: 507-511.

Padayatty SJ, Katz A, Wang Y, Eck P, Kwon O, Je-Hyuk L, Chen S, Corpe C, Dutta A, Dutta SK, Levine M. 2003. Vitamin C as an antioxidant: Evaluation of its role in disease prevention. J. Am. Col. Nutr., 22: 18-35.

Paiva SA, Russell RM. 1999. Beta-carotene and other carotenoids as antioxidants. $J$. Am. Coll. Nutr., 18(5): 426-433.

Pockros PJ, Jeffers L, Afdhal N, Goodman ZD, Nelson D, Gish RG, Reddy KR, Reindollar R, Rodriguez-Torres M, Sullivan S, Blatt LM, Faris-Young S. 2007. Final results of a double-blind, placebo-controlled trial of the antifibrotic efficacy of interferon-gammalb in chronic hepatitis $\mathrm{C}$ patients with advanced fibrosis or cirrhosis. Hepatology, 45(3): 569-578.

Seifert WF, Bosma A, Hendriks HF, van Leeuwen RE, van Thiel-de Ruiter GC,
Seifert-Bock I, Knok DL, Brouwer A. 1995. Beta-carotene (provitamin A) decreases the severity of $\mathrm{CCl}_{4}$-induced hepatic inflammation and fibrosis in rats. Liver, 15(1): 1-8.

Wallace K, Burt AD, Wright MC. 2008. Liver fibrosis. Biochem. J., 411(1): 1-18.

Wamutu S, Francque S, Chatterjee S, Musisi E, Muyombya GW, Van Marck E, Michielsen P, Bimenya GS. 2011. Effects of vitamin $\mathrm{C}$ and $\beta$-carotene pre-treatment on liver damage induced by short-term $\mathrm{CCl}_{4}$ administration in rats. Int. J. Biol. Chem. Sci., 5(2): 824-834.

Wardi J, Reifen R, Aeed H, Zadel L, Avni Y, Bruck R. 2001. Beta carotene attenuates experimentally induced liver cirrhosis in rats. Isr. Medic. Assoc. J., 3: 151-154.

Wasmuth HE, Weiskirchen R. 2010. Pathogenesis of liver fibrosis: modulation of stellate cells by chemokines. $Z$. Gastroenterol., 48(1): 38-45. 